University of Nebraska - Lincoln

DigitalCommons@University of Nebraska - Lincoln

Faculty Publications, Department of Psychology

Psychology, Department of

2016

\title{
Psychological Distress and Revictimization Risk in Youth Victims of Sexual Abuse
}

\author{
Samantha L. Pittenger \\ University of Nebraska-Lincoln, samantha.friedenberg@gmail.com \\ Alayna Schreier \\ University of Nebraska-Lincoln, alayna.schreier@gmail.com \\ Katie Meidlinger \\ University of Nebraska \\ Jessica K. Pogue \\ University of Nebraska - Lincoln, jpogue@unl.edu \\ Kate Theimer \\ University of Nebraska-Lincoln, katetheimer4@gmail.com \\ See next page for additional authors
}

Follow this and additional works at: https://digitalcommons.unl.edu/psychfacpub

Part of the Child Psychology Commons, Clinical Psychology Commons, Counseling Commons, Developmental Psychology Commons, and the Health Psychology Commons

Pittenger, Samantha L.; Schreier, Alayna; Meidlinger, Katie; Pogue, Jessica K.; Theimer, Kate; Flood, Mary Fran; and Hansen, David J., "Psychological Distress and Revictimization Risk in Youth Victims of Sexual Abuse" (2016). Faculty Publications, Department of Psychology. 811.

https://digitalcommons.unl.edu/psychfacpub/811

This Article is brought to you for free and open access by the Psychology, Department of at DigitalCommons@University of Nebraska - Lincoln. It has been accepted for inclusion in Faculty Publications, Department of Psychology by an authorized administrator of DigitalCommons@University of Nebraska - Lincoln. 


\section{Authors}

Samantha L. Pittenger, Alayna Schreier, Katie Meidlinger, Jessica K. Pogue, Kate Theimer, Mary Fran Flood, and David J. Hansen 
Published in Journal of Interpersonal Violence (2016), $31 \mathrm{pp.}$

DOI: $10.1177 / 0886260516658755$

Copyright (C) 2016 Samantha L. Pittenger, Alayna Schreier, Katie Meidlinger, Jessica K. Pogue, Kate Theimer, Mary Fran Flood, and David J. Hansen.

Published by SAGE Publications. Used by permission.

\title{
Psychological Distress and Revictimization Risk in Youth Victims of Sexual Abuse
}

\author{
Samantha L. Pittenger, Alayna Schreier, Katie Meidlinger, \\ Jessica K. Pogue, Kate Theimer, Mary Fran Flood, \\ and David J. Hansen
}

University of Nebraska-Lincoln

\begin{abstract}
Psychological distress, including depression and anxiety, has been associated with increased risk for sexual revictimization in youth who have experienced child sexual abuse. The present study utilized assessment information from treatment seeking youth with histories of sexual abuse to explore specific risk indicators for revictimization-risk taking, social problems, maladaptive cognitions, and posttraumatic stress-that may be indicated by self-reported distress. The relationship between initial levels of distress and change in symptoms over a 12-week course of treatment was also explored. Participants were 101 youth referred to a child-focused therapeutic group for victims of sexual abuse, 65 youth referred to an adolescentfocused group, and their non-offending caregivers. Results revealed that when combined into a distress score, depression and anxiety were associated with delinquent behaviors, interpersonal difficulties, maladaptive cognitions, and posttraumatic stress symptoms for child and adolescent group participants at presentation to treatment. Children exhibited improvement on measures of interpersonal difficulties, maladaptive cognitions, and self-reported posttraumatic stress disorder (PTSD) symptoms. Adolescents exhibited less change over time, with significant improvement on self-reported social problems and PTSD only. Higher psychological distress was associated with less improvement in regard to negative expectations of abuse impact for child group participants. The findings suggest that distress indicates the presence of specific revictimization risk indicators, helping to identify targetable symptoms for intervention. Therefore, screening for psychological distress after discovery of sexual abuse may help detect youth at higher risk for revictimization and guide treatment.
\end{abstract}


Keywords: sexual abuse, child abuse, treatment/intervention, revictimization

Within the United States, $24.7 \%$ of women and $16 \%$ of men endorse experiencing sexual abuse as children or adolescents (Centers for Disease Control and Prevention, 2010) and many experience a myriad of clinical problems, problematic sexualized behaviors, and neurobiological dysfunction (Putnam, 2003). Child sexual abuse (CSA) also heightens risk for subsequent sexual victimization throughout the life span, a phenomenon that has been labeled revictimization (Classen, Palesh, \& Aggarwal, 2005). Emerging evidence suggests that revictimization occurs prior to adulthood in the forms of sexual abuse by additional perpetrators and sexual assault, with prevalence rates between $20 \%$ and 39\% (Finkelhor, Ormrod, \& Turner, 2007; Swanston et al., 2002). Thus, while there is no set pattern of outcomes, there is substantial evidence showing that sexually abused youth are (a) more likely than their non-abused peers to develop a variety of behavioral and psychological symptoms and (b) more likely than their non-abused peers to experience sexual revictimization in childhood, adolescence, and adulthood. Research on sexual revictimization to date has largely focused on linking these two notions, specifically, how psychological and behavioral symptoms might increase the risk for revictimization.

Studies examining the causes of revictimization have often used operational definitions that preclude experiences as a minor. Due to this, adult samples provide much of the knowledge base regarding revictimization, frequently via retrospective studies, although empirical examinations of children and adolescents are emerging. Based on literature to date, the following abuse sequelae have been identified as risk factors for revictimization: risk taking, interpersonal difficulties, maladaptive cognitions, and posttraumatic stress disorder (PTSD; Arata, 2002; Classen et al., 2005; Risser, Hetzel-Riggin, Thomsen, \& McCanne, 2006). These constructs also map on to Finkelhor and Browne's (1985) traumagenic dynamic model, described below, which provides a framework for understanding the consequences of CSA.

Substance or alcohol abuse and sexual risk behaviors often arise as consequences of CSA and both are associated with higher risk for revictimization in adulthood (Filipas \& Ullman, 2006). This relationship has also been examined in adolescent females for whom multiple sexual partners, frequent sexual activity, prostitution, criminal behaviors, and delinquency are implicated in heightening risk for revictimization (Collins, 1998). Adult research has further shown that CSA victims may also have inappropriate views of inti- mate relationships emphasizing the importance of sexual en- 
gagement (Cloitre, 1998), thus placing them in risky or sexually exploitive situations. CSA also impacts youth's affect regulation, interpersonal relationships, and how they think about themselves and their surroundings (Putnam, 2003). For example, maladaptive cognitions such as self-blame and shame may prevent children and adolescents from seeking out healthy relationships and increase vulnerability to engage in abusive relationships (Finkelhor \& Browne, 1985). Studies including adult women have found that those who report sexual revictimization also indicate difficulties in the interpersonal areas of sociability, submissiveness, intimacy, responsibility, and control (Cloitre, Scarvalone, \& Difede, 1997). In addition, it is suspected that characterological and behavioral self-blame may mediate the relationship between CSA and adult sexual revictimization whereby women attributing responsibility to themselves use fewer adaptive coping skills thus making them vulnerable to perpetration (Arata, 2002). Posttraumatic stress symptoms have also been proposed as mediators of revictimization, although they have not been examined in this capacity in youth samples. Risser and colleagues (2006) found that hyper- arousal symptoms hindered the ability to sense real from perceived danger, placing victims with PTSD symptoms in risky situations. Trauma symptoms, including intrusive thoughts and emotional reactivity, may also be exacerbated by avoidant coping styles, which further strengthen the CSA- revictimization relationship (Fortier et al., 2009). In addition, dissociation, a type of avoidance symptom of PTSD, may decrease awareness of one's surroundings and the ability to detect danger (Chu, 1992).

Despite the multiple proposed theories of revictimization, there have been few prospective studies investigating mediators of sexual revictimization or including youth samples. These shortcomings leave questions regarding risk factors for revictimization in children and adolescents; however, it is plausible that the risk factors outlined in the adult literature also apply to youth, particularly when considering the four tenets of traumagenic dynamics: traumatic sexualization, betrayal, powerlessness, and stigmatization (Finkelhor \& Browne, 1985). First, traumatic sexualization corresponds to the increase in risky sexual behaviors and possibly in engagement in risky or criminal activity, both of which increase the risk for revictimization. Betrayal is hypothesized to contribute to problems in interpersonal relationships such as dependency, misaligned trust, and desperate needs for security which often lead to abusive relationships. Powerlessness, a maladaptive cognition also related to learned helplessness (Peterson \& Seligman, 1983), often leads to feelings of fear and anxiety which are characteristic of posttraumatic stress and may prevent victims' ability to protect themselves 
from danger, as stated above. Finally, stigmatization and self-labeling may lead victims to join marginalized groups thereby increasing risk for engagement in delinquent and dangerous behaviors.

Exploring revictimization within childhood and adolescence, one large- scale, prospective study of youth has shown that general distress predicts revictimization within 1 year of initial interview (Cuevas, Finkelhor, Clifford, Ormrod, \& Turner, 2010). Cuevas and colleagues' study is pivotal in that it shows an actual link between abuse sequelae and revictimization within childhood and adolescence through a prospective research design. Although the goal of many interventions for victims of CSA is to alleviate symptoms, Cuevas and colleagues (2010) also argued that treatment should serve as a method of secondary prevention, something that Marx, Calhoun, Wilson, and Meyerson (2001) have sought to examine with adults. In their efficacy study exploring the impact of a preventive intervention for victims of sexual assault, Marx and colleagues found a significant decrease in rates of revictimization for those attending a 2-day educational program. They achieved this positive outcome by providing education about sexual assault, safety behaviors, and common reactions to sexual trauma as well as psychoeducation and skills practice in the areas of problem solving, coping with emotions, assertiveness, and communication.

The current study sought to apply knowledge gained from adult studies by examining the relationship between distress and the specific revictimization risk indicators described above in children and adolescents presenting for treatment following the discovery of CSA. We hypothesized that greater self- reported distress-defined as an aggregate of depression and anxiety-at presentation to treatment would predict higher levels of risk taking (e.g., sexual risk behaviors and delinquency), interpersonal difficulties, maladaptive cognitions, and posttraumatic stress. Whereas Cuevas and colleagues conceptualized distress as an aggregate of depression, anxiety, and anger symptoms, for the purposes of this study, anger was not included in the dis- tress score which is consistent with prior adult research examining the link between distress and revictimization (Orcutt, Cooper, \& Garcia, 2005). We also hypothesized that revictimization risk indicators would decrease over the course of a 12-week cognitive-behavioral group intervention, following from Marx and colleagues' (2001) findings. Finally, understanding that some sexually abused children fail to improve and that depression reported prior to treatment may be associated with posttreatment symptom severity (Deblinger, Mannarino, Cohen, \& Steer, 2006), we expected initial distress to influence change in symptoms over the course of treatment. Specifically, we expected that greater distress at presentation to 
treatment would be associated with less change in risk factors for revictimization.

\section{Method}

\section{Participants and Procedures}

Participants included children $(n=101)$ and adolescents $(n=65)$ as well as their non-offending caregivers who presented to therapeutic groups for sexually abused youth. Child-focused groups typically include children between the ages of 7 and 12, and adolescent-focused groups typically include adolescents between the ages of 13 and 18. However, participant age, developmental level, and availability of other group members were considered when assigning youth to the child or adolescent-focused groups; as such, there has been overlap in the 11 to 14 age range across groups. For example, a typically developing 12-year-old would be placed in an adolescent group comprised of 13- to 14-year-olds compared with a child group with 7- to 8year-old participants. Due to these considerations, there was one 13-yearold and one 14-year-old in the child group, and one 11-year-old and four 12year-old participants in the adolescent group. All participants had reported at least one incidence of CSA to authorities, received services at the local Child Advocacy Center (CAC), and had been referred to the therapeutic services of Project SAFE (Sexual Abuse Family Education; Tavkar \& Hansen, 2011). Project SAFE does not require that youth present with clinical level symptoms to receive services, therefore the sample was heterogeneous in symptom presentation and likely to represent the general population of youth who have experienced sexual abuse (Sawyer \& Hansen, 2014).

Children ranged from 7 to 14 years old $(M=10.1 ; S D=1.7): 72$ were female $(71 \%)$ and 29 were male (29\%). The majority of children were European American (80\%), 6\% were Hispanic, 6\% were African American, $6 \%$ were Biracial or Multiracial, and $1 \%$ were Native American. Information regarding ethnicity was missing for one child. Children attended an average of nine ( $S D=3$, range $=1-12$ ) group sessions, with $50 \%$ attending nine or more. Children's non-offending caregivers ranged from 23 to 55 years old $(M=35.8 ; S D=6.5)$. The majority were female $(N=88 ; 87 \%) ; 84 \%$ were European American, 6\% were Hispanic, 3\% were Biracial, and 1\% each were African American, Native American, and Multiracial. Most caregivers were biological mothers (77\%), 11\% were biological fathers, $4 \%$ were foster mothers, $3 \%$ were grandmothers, $2 \%$ were step or adoptive mothers, and 
$1 \%$ were foster fathers.

Adolescents ranged from 11 to 18 years old $(M=14.7 ; S D=1.5)$; 60 were female (92\%) and five were male (8\%). Fifty adolescents were European American (77\%), three were Hispanic (5\%), two were African American (3\%), two were Native American (3\%), and five were Biracial or Multiracial (8\%). Information regarding ethnicity was missing for three adolescents. Adolescents attended eight sessions, on average $(S D=3$, range $=1$ 12), with 50\% attending nine or more. Caregivers of adolescents ranged from 29 to 72 years old $(M=41.2 ; S D=7.9)$. Similar to children, the majority of adolescents' caregivers were female (77\%), European American ( $82 \%)$, and bio- logical mothers $(71 \%)$. About $5 \%$ reported being of Hispanic ethnicity, 2\% African American, and 3\% Biracial. Caregivers also included biological fathers $(12.3 \%)$, step or adoptive mothers (5\%), step or adoptive fathers ( $3 \%)$, foster mothers (2\%), and foster grandmothers ( $2 \%)$.

Participants and their caregivers completed an assessment battery at preand post treatment including demographic and abuse history forms and the measures described below. Demographic and abuse history forms collected information about gender, age, ethnicity, family history, the child's immediate environment, age at first abuse, frequency, duration, and severity of abuse, relationship to perpetrator, and abuse discovery. Caregivers provided informed consent to participate in research and were compensated for completion of the pretreatment assessment battery. All procedures were approved by the University's Institutional Review Board.

\section{Overview of Project SAFE}

Project SAFE is a 12-week, cognitive-behavioral, parallel group treatment program for children who have experienced CSA and their non-offending family members (for description, see Tavkar \& Hansen, 2011). Doctoral student therapists lead services, offered at no cost to families. Developers of Project SAFE constructed separate treatment manuals for children and adolescents enabling groups to be formed so that members are of similar developmental levels. Therapists are also able to tailor information for group members' specific needs within those age groups, particularly sexual education, peer relationships, and coping with emotions. Providing separate groups for children and adolescents serves to optimize their group experience (Sturkie, 1994) and increase the effectiveness of treatment (Avinger \& Jones, 2007; Corder, Haizlip, \& DeBoer, 1990). This manualized program has exhibited efficacy in improving youth behavior and functioning following abuse across a variety of symptom domains and symptom severity levels 
(Hubel et al., 2014). Prior evaluations of Project SAFE have indicated that youth experience reductions in anxiety and posttraumatic stress symptoms as well as increases in self-esteem as a result of attending treatment (Hsu, 2003; Hubel et al., 2014). Project SAFE's three primary goals are to minimize stigmatization, enhance emotional awareness and coping, and empower children to prevent future abuse. These goals are reached through addressing issues in the areas of self, relationships, and sexuality. Specific topics relevant to future well-being and safety include emotion education and coping, appropriate ways to seek familial and social support, developmentally appropriate sexual education, assertiveness, and risk recognition.

\section{Measures}

Distress. Two measures were selected to represent the anxiety and depression components of psychological distress. First, the Children's Depression Inventory (CDI; Kovacs, 1992), a 27-item, self-report questionnaire for children and adolescents aged 7 to 17 years, was used to assesses symptoms of depression. Items on this measure load onto subscales measuring negative mood, interpersonal difficulties, negative self-esteem, ineffectiveness, and anhedonia. Total raw scores can reach 54 with a clinical cutoff of 20 and $T$ scores above 64 represent clinically significant symptoms. Using a normative sample of 1,266 male and female public school students divided into two age ranges (7-11 years and 12-17 years), the authors found good internal consistency with alphas between .71 and .89 (Kovacs, 1992). For the purposes of the present study, the Total score was used as a measure of depressive symptoms ( $\alpha=.89$ for current sample). Second, the Revised Children's Manifest Anxiety Scale (RCMAS; Reynolds \& Richmond, 1985), a self-report measure of anxiety for youth aged 6 to 19 years, was used to assess anxiety symptoms. This 37-item scale provides a Total Anxiety score as well as subscale scores of Physiological Anxiety, Worry/Oversensitivity, Social Concerns/Concentration, and a Lie Scale. The measure has good reliability ( $\alpha=$ .83 in standardization sample, $\alpha=.85$ in current sample) and provides clinical cutoff scores based on age and gender (Reynolds \& Richmond, 1978). The Total Anxiety score was aggregated with the CDI total score to represent psychological distress.

Risk taking. Two aspects of risk taking were assessed: rule-breaking behavior and sexual behavior. Rule breaking was assessed via parent-report for all youth through the Child Behavior Checklist (CBCL; Achenbach \& Rescorla, 2001), a 113-item, standardized measure for parents of youth aged 
4 to 18 years. Scales on the CBCL have been standardized based on age and gender and have good reliability (Achenbach \& Rescorla, 2001). The Delinquent Behaviors subscale was included as a measure of rule breaking and exhibited acceptable internal consistency in this sample $(\alpha=.72)$. Adolescents also completed the Youth Self-Report (YSR; Achenbach \& Rescorla, 2001), a 112-item self-report measure including Likert-type items as well as open- ended questions covering physical problems, strengths, and concerns designed to parallel the CBCL. The YSR was normed on 1,057 children aged 11 to 18 years of various ethnicities and socioeconomic status. Again, the Delinquent Behaviors subscale, which exhibited excellent internal consistency in the present sample ( $\alpha=.99)$, was used to measure engagement in rulebreaking behavior. To measure sexual risk taking, adolescents completed the Adolescent Clinical Sexual Behavior Inventory-Self-Report (ACSBI-S; Friedrich, Lysne, Sim, \& Shamos, 2004), a 45-item screening measure of sexual behaviors, knowledge, and interests for youth aged 12 to 18 years. Internal consistency for the total scale is .86, and test-retest reliability is .74 (Friedrich et al., 2004), with Cronbach's alpha of .73 for the present sample.

Interpersonal difficulties. Three instruments were used to assess interpersonal difficulties through both self- and parent-report. First, all youth completed the Weekly Problems Scale-Child Report Version (WPS-C; Sawyer, Tsao, Hansen, \& Flood, 2006) which was developed by Project SAFE researchers to briefly assess multiple dynamic domains of child functioning. On this 11-item scale, children and adolescents are asked to best describe their feelings and interactions during the past week. For the purposes of the current study, only the Problem Peer and Parental Interactions subscale (PPPI) was used. This subscale exhibits good internal consistency with an alpha coefficient of .77 (Sawyer et al., 2006). Items included on the PPPI are as follows: "I get along with my friends," "I have good talks with [the person who is bringing you to group]," "I get along with [the person who is bringing you to group]," and "I feel like [the person who is bringing you to group] is good to me." In response to these questions, youth mark whether these items described their feelings or interactions never, almost never, a little of the time, some of the time, most of the time, or all of the time. In addition, the YSR Social Problems subscale ( $\alpha=.99$ for current sample) was considered as an additional self-report measure of interpersonal problems for adolescents only, and parent-report on the CBCL Social Problems subscale ( $\alpha=.69$ for current sample) was used for both children and adolescents. 
Maladaptive cognitions. This study measured four types of maladaptive cognitions: self-blame, powerlessness, negative expectations of abuse impact, and negative self-appraisal. Self-blame and powerlessness were assessed via the Self-Blame/Guilt and Empowerment subscales of the Children's Impact of Traumatic Events Scale-Revised (CITES-R; Wolfe, Gentile, Michienzi, Sas, \& Wolfe, 1991), a 78-item Likert-type scale normed on two samples totaling 287 youth aged 7 to 16 years (Chaffin \& Shultz, 2001; Wolfe et al., 1991). Prior psychometric assessment of the CITES-R found internal consistency for subscales to range between .56 and .79, and most subscales were able to note change due to treatment (Chaffin \& Shultz, 2001). In the present sample, Cronbach's alphas were .64 and .56 for SelfBlame/Guilt and Empowerment, respectively. These subscales were included to measure maladaptive belief risk indicators, as the scales have previously been used to represent the traumagenic dimensions of stigmatization and powerlessness (Celano, Hazzard, Webb, \& McCall, 1996). Negative expectations of abuse impact were assessed using the Post Sexual Abuse Expectations Scale-Youth (PSAES-Y), also developed for Project SAFE. The PSAES-Y assesses children's expectations of the impact of sexual abuse on their own behavior, emotional adjustment, and social and familial relationships. The scale includes 10 items on which youth respond using a Likerttype scale $(1=$ not at all to $5=a$ lot $)$ to reflect how much each statement describes them and responses are summed to derive the total score. The PSAES-Y has excellent internal consistency $(\alpha=.92$; Meidlinger et al., 2014). Finally, negative self-appraisal was assessed using the Coopersmith Self-Esteem Inventory (SEI; Coopersmith, 1981), a 58-item self-report measure designed to assess youth's attitudes about them- selves in social, family, academic, and personal contexts which also includes an eight-item lie scale. Self-esteem is measured as the child's approval or disapproval of him or herself. The SEI exhibits adequate internal consistency ( $\alpha=.80$ to .92) and has adequate construct and concurrent validity. The cur- rent study used the Total Self score to assess maladaptive cognitions surrounding selfimage and internal consistency alpha was .99 in the present sample. This score is comprised of 50 items from the inventory and ranges from o to 100 with means of 70 to 80 in the original development sample (Coopersmith, 1981). Higher scores indicate more self-esteem.

PTSD. The CITES-R PTSD scale (Wolfe et al., 1991), which includes items relating to intrusive thoughts, hyperarousal, avoidance, and sexual anxiety, served as a measure of the posttraumatic stress symptom risk indicator. 
Crouch, Smith, Ezzell, and Saunders (1999) found good internal consistency for items on this scale with their sample of 8 - to 17-year-old sexually abuse youth. Cronbach's alpha was .59 in the present sample.

\section{Analyses}

Variables associated with risk for revictimization, referred to as "risk indicators," were selected based on the research literature described above. Statistical analyses were performed separately for children and adolescents, as they experienced varying treatment protocols to address developmental differences and adolescents completed two additional self-report measures (i.e., ACSBI-S and YSR). Data were not normally distributed, therefore nonparametric tests were used to explore bivariate relationships, and Blom's (1958) rank-based inverse normal transformation method was used to normalize data as to meet the assumptions of linear regression analyses. Nonparametric Spearman's rank correlation coefficient was used to examine bivariate relationships between abuse and demographic characteristics and risk indicators to account for non-normal data. Hierarchical linear regression models were used to explore the relationships between distress and risk indicators while accounting for abuse and demographic characteristics identified as potential covariates. For each model, Step 1 included any identified covariates, and Step 2 included distress as a predictor. This study used a multiple-indicator approach whereby more than one measure was used to examine constructs of interest. Thus, the family-wise error rate for comparisons made within each category of risk factors was corrected using the Holm-Bonferroni method (Holm, 1979) to reduce the risk of inflating the Type I error rate. Change scores were calculated by subtracting reported scores at pretreatment from reported scores at posttreatment. These scores were then transformed using Blom's method to normalize scores and for consistency between pretreatment and pre- to posttreatment change analyses. All analyses were performed using SPSS version 22.0 (IBM Corp, 2013).

\section{Results}

\section{Distress Score}

A distress score was calculated using methodology similar to that described by Cuevas and colleagues (2010), here defined as an aggregate of depression and anxiety. The $z$ scores, calculated using sample statistics from the child 
and adolescent groups in regard to responses on the CDI Total and RCMAS Total Anxiety scores, were summed to derive a total distress score, hereafter referred to as "distress." Anxiety and depression were positively correlated for both children, $r=.56, p<.001$, and adolescents, $r=.70, p<.001$. Distress scores ranged from -3.24 to $5.81(M=0$; $S D=1.77)$ for children and -4.38 to $4.91(M=0 ; S D=1.84)$ for adolescents.

\section{Abuse Specific Information}

Children. On average, children were 8 years old $(S D=2.3)$ when sexual abuse first occurred and they experienced abuse for a duration of about 1 year, with an average age of 9 years $(S D=2.1)$ at the time abuse ended. Frequency of abuse ranged from 1 time (27\%) to more than 100 times $(5 \%)$. The majority of children experienced penile or digital penetration $(49 \%$; including oral, anal, and/or vaginal) whereas 37\% experienced contact, non-penetrative forms of abuse, and $7 \%$ experienced non-contact abuse. Physical force was reported in $23 \%$ of cases, and $5 \%$ of cases involved childto-child acts.

Adolescents. On average, adolescents were 11 years old $(S D=2.9)$ at the time of first abuse occurrence and were 13 years old $(S D=2.7)$ when abuse ended. Frequency of abuse ranged from 1 time (31\%) to more than 100 times (8\%). The majority of adolescents experienced penile or digital penetration (59\%; including oral, anal, vaginal) whereas $26 \%$ experienced contact, nonpenetrative forms of abuse, and $8 \%$ experienced non-contact abuse. Force was reported in $37 \%$ of cases.

\section{Abuse and Demographic Characteristics and Distress}

Bivariate analyses were used to explore the relationship between various demographic and abuse characteristics and distress. Ethnicity, gender, intrusiveness of abuse act, and perpetrator relationship to child were dummy coded for analyses such that a code of "1" represented responses of European American, female, penetration, and intra-familial perpetration, respectively. A "O" code on these variables indicated non-European American, male, the absence of penetration, and extra-familial perpetration. Spearman's rank correlation coefficients exploring continuous and dummy coded variables indicated that adolescents identifying as non-European American reported higher distress, $r_{\mathrm{S}}=.305, p=.016$. This relationship was not significant for children, nor were relationships between distress and gender, 
intrusiveness of abuse acts, age at the time of treatment, age at abuse onset, relationship to perpetrator, or duration of abuse (in months) for children or adolescents.

\section{Abuse and Demographic Characteristics and Risk Indicators at Presenta- tion to Treatment}

Bivariate analyses were also run to explore the relationships between the various abuse and demographic information described above and risk indicators for revictimization. Many of the variables selected as risk indicators were non-normally distributed, as is evident in means and standard deviations displayed in Table 1; therefore, non-parametric tests were used to examine bivariate relationships. Using Spearman's rho (see Tables 2 and 3), it was evident that various characteristics were associated with risk indicators. Specifically, at presentation to treatment, children who experienced penetrative abuse reported higher feelings of empowerment on the CITES$\mathrm{R}$; children identifying as European American and those who were older reported more problematic peer and parental interactions on the WPS-C; and children whose perpetrator was in the immediate family were rated as having more social problems by parents. For adolescents, having an intrafamiial perpetrator was associated with fewer parent-reported social problems. In addition, those adolescents enduring a longer period of abuse reported more negative perceptions of abuse impact. Finally, adolescents identifying as European American reported more self-blame and more empowerment than those identifying as an ethnic minority.

\section{Child Group Revictimization Risk}

Distress and risk indicators at pretreatment. Linear regression models with risk indicators as criterion variables were used to explore the relationship between distress and risk for revictimization. To accommodate for covariates identified in the sections above, hierarchical regression modeling was used whereby the covariates of age, ethnicity, intrusiveness of abuse acts (i.e., penetration or no penetration), and relationship to the abuse perpetrator were included in the first step and distress was added in the second step. As shown in Table 4, the addition of distress resulted in a significant $R^{2}$ change for every model except CBCL Social Problems; however, this model did account for a significant proportion of the variance with parents reporting fewer social problems for children abused by family members, $F(5,87)=2.52, p=.04$. As self- reported distress increased, children and 
parents reported more problems related to risky behaviors, CBCL Delinquency subscale: $F(5,82)=3.06, p=.01$; social problems, WPS-C PPPI: $F(5$, $77)=5.04, p=.001 ;$ maladaptive cognitions, CITES-R Self-Blame/Guilt: $F(5$, $91)=4.17, p=.002$, CITES-R Empowerment: $F(5,91)=4.15, p=.002$, PSAES-Y: $F(5,44)=2.58, p=.04$, and SEI: $F(5,91)=24.79, p<.001$; and posttraumatic stress symptoms, CITES-R PTSD: $F(5,91)=6.86, p<.001$. All effects remained significant after correcting for the family-wise error rate using the Holm-Bonferroni method.

Change in risk indicators over time. Related samples Wilcoxon signed rank tests are presented in Table 1 and were used to assess change in risk indicators between pre- and posttreatment. Children showed improvement over the course of treatment in regard to levels of problematic social interactions, self- blame and guilt, feelings of empowerment, expectations of abuse impact on future functioning, self-esteem, intrusive thoughts, avoidance, and hyper- arousal symptoms. The number of sessions attended was not associated with pre-to-post treatment change in any risk indicators (Spearman's rank correlation coefficient $p s<.05$ ).

Distress and pre- to posttreatment change in risk indicators. Similar regression models were used to explore the effect of initial distress on change in risk indicators over the course of treatment, including the covariates of child age, gender, ethnicity, penetration or no penetration, and perpetrator relationship. As shown in Table 4 , the addition of distress as a predictor resulted in a significant increase in the proportion of variance accounted for only in the model examining the PSAES-Y. In this case, change in expectations of abuse impact were less robust when children presented to treatment with higher self- reported distress, $F(5,24)=2.87, p=.04$. Abuse and demographic characteristics significantly predicted change in self-report of social problems on the WPS-C PPPI scale, $F(5,46)=3.01, p=.02$, such that youth identifying as European American exhibited less improvement in positive peer and parental interactions while those youth with an intra-familial perpetrator exhibited greater improvement.

The following models did not result in significant $F$ tests, despite significant $R^{2}$ changes and regression coefficients for the distress variable: CITES-R Empowerment, $F(5,61)=1.96, p>.05$, and SEI, $F(5,60)=1.22, p$ $>$.05. In addition, older children tended to show less improvement as rated by parents on the CBCL Social Problems subscale, $F(5,54)=1.71, p>.05$. Finally, neither initial distress nor abuse or demographic characteristics significantly predicted change on the CBCL Delinquency subscale, $F(5,54)=$ 
$.47, p>.05$, and the CITES-R Self-Blame/Guilt, $F(5,61)=.48, p>.05$, and PTSD, $F(5,61)=.40, p>.05$.

\section{Adolescent Group Revictimization Risk}

Distress and risk indicators at pretreatment. Regression models, presented in Table 5, were used to predict various risk indicators at presentation to treatment. The identified covariates of age at abuse onset, ethnicity, duration of abuse, use of penetration, and relationship to the abuse perpetrator were included in the first step of each model, and distress was added in the second step. Significant $R^{2}$ changes suggest that higher distress predicted the presence of worse symptoms on the YSR Delinquency, $F(6,51)=2.55, p$ $=.03$, and Social Problems subscales, $F(6,51)=4.72, p<.001$, the CITES-R Empowerment subscale, $F(6,53)=2.84, p=.02$, SEI, $F(6,53)=19.06, p<$ .001 , PSAES-Y, $F(6,31)=3.01, p=.02$, and the CITES-R PTSD scale, $F(6,53)$ $=7.17, p<.001$. These effects remained significant after correcting for the family-wise error rate using the Holm-Bonferroni method.

Although a significant $R^{2}$ change was present for the model predicting the CITES-R Self-Blame/Guilt subscale, $F(6,53)=1.99, p=.09$, the $F$ test resulted in only a trend toward significance. Neither distress nor abuse or demographic covariates predicted initial report on the ACSBI-S, $F(6,32)$ $=.74, p=.62$, CBCL Delinquency, $F(6,53)=1.75, p=.13$, or Social Problems subscales, $F(6,53)=1.23, p=.31$, or the WPS-C PPPI, $F(6,52)=1.10, p=$ .38 .

Change in risk indicators over time. Related samples Wilcoxon signed rank tests presented in Table 1 were used to assess adolescents' change in risk indicators between pre- and posttreatment. Adolescents reported a significantly lower median score in regard to social problems, intrusive thoughts, and hyperarousal symptoms over the course of the 12-week treatment. Similar to children, the number of sessions attended was not associated with pre- to posttreatment change in any risk indicators, all Spearman's rank correlation coefficients returned nonsignificant probabilities for rejecting the null hypotheses.

Distress and pre- to posttreatment change in risk indicators. Regression models, presented in Table 5, were used to explore the effect of initial distress on change in risk indicators over the course of treatment, including the covariates of adolescent age at abuse onset, ethnicity, use of penetration, relation- ship to perpetrator, and duration of abuse. Despite significant 
reductions in reported symptoms, distress at presentation to treatment was not associated with any change in problems reported over treatment.

\section{Discussion}

The purpose of the present study was to apply knowledge gained from adult revictimization research to youth samples to understand the role of postsexual abuse psychological distress in predicting a variety of risk factors for sexual revictimization. Sexual abuse victims are at higher risk of subsequent victimization in comparison with non-abused peers (Classen et al., 2005), although there is limited research examining mediators and moderators of revictimization in youth. At least one prospective study examining revictimization in youth has implicated psychological distress as a predictor of subsequent sexual and non-sexual victimization (Cuevas et al., 2010). Adult literature, on the contrary, is rich with evidence that various individual, cognitive, and behavioral factors increase the likelihood of revictimization. The present study hypothesized that (a) heightened distress at presentation to treatment would predict more problems related to engagement in risky behaviors, interpersonal difficulties, maladaptive cognitions, and posttraumatic stress symptoms, (b) these symptoms would improve over the course of treatment, and (c) heightened distress at presentation to treatment would predict change in symptoms over the course of treatment. Children and adolescents were examined independently due to developmental differences and receipt of differing treatment protocols.

Results suggested that self-reported distress, when considered an aggregate of depression and anxiety, predicted report of many revictimization risk indicators for both children and adolescents. Specifically, through selfreport, children and adolescents showed increases in interpersonal difficulties, mal- adaptive cognitions, and posttraumatic stress symptoms when subjectively reporting more distress. In addition, adolescents identified increased risky behaviors in themselves when experiencing more depression and anxiety, and this same effect was present for parent-report of children's delinquent behaviors.

Risky behaviors may develop as a coping mechanism to manage emotional discomfort (Filipas \& Ullman, 2006). Results of the present study are consistent with this notion, as distress predicted higher self- and parentreported delinquency for adolescents and children, respectively. Aside from the inherent dangers of engaging in risk taking, drug and alcohol use may increase risk for sexual revictimization (Fargo, 2009), thus perpetuating a

cycle of victimization. There was a similar relationship between distress 
and relationship problems, consistent with our hypothesis and prior research regarding the link between depression and interpersonal functioning (Lam, Schuck, Smith, Farmer, \& Checkley, 2003). This raises concern given prior findings that adolescents' satisfaction with social relationships predicts the likelihood of revictimization (Collins, 1998), as well as evidence that deficits in interpersonal functioning are associated with repeated experiences of sexual victimization in adulthood (Cloitre et al., 1997). Also as hypothesized, participants reporting higher levels of psychological distress endorsed a number of maladaptive cognitions and reported concern about PTSD at presentation to treatment. This supports prior research showing that poorer psychological functioning is often associated with maladaptive beliefs and trauma symptoms in victims of CSA (Wenninger \& Ehlers, 1998). These problems are harbingers of revictimization as cognitive and posttraumatic stress symptoms may mediate the relationship between CSA and revictimization (Risser et al., 2006).

A number of variables examined did not significantly relate to selfreported distress at presentation to treatment. For children, this included parent-reported social problems and for adolescents, self-report of sexual behaviors, parent-report of social problems and delinquent behaviors, and self-report of problematic peer and parental interactions. Many multi- informant studies have documented the issue of discrepant reports between parents and children, noting that parents underreport problems especially as youth age through adolescence (Verhulst \& van der Ende, 1992). It is possible that parents did not serve as accurate informants in the present study. The most interesting of these null findings was that between distress and adolescent sexual risk taking. Correlational analyses suggested a significant, positive relationship between distress and sexual behavior problems although this effect was not present in multivariate analyses. Sexual behaviors were also positively related to self- and parent-reported risk taking and self-reported social problems, and negatively correlated with self-esteem (see Table 3). The limited research available on the phenomenon of sexual revictimization within adolescence has shown that more frequent consensual sexual activity (Fargo, 2009; Krahe, Scheinberger-Olwig, Waizenhöfer, \& Kolpin, 1999), early onset sexual activity and sexual risk taking behaviors (Fergusson, Horwood, \& Lynskey, 1997), and number of sexual partners (Bramsen et al., 2013), all mediate the relationship between CSA and adolescent revictimization. The present findings suggest that sexual risk taking may be less influenced by distress than other factors such as maladaptive cognitions and interpersonal difficulties, which points to multiple pathways that lead to revictimization. 
Contrary to hypotheses, only a selection of risk indicators improved over the course of treatment. For children, the most robust improvements were reported for self-blame and guilt, empowerment, self-esteem, and posttraumatic stress symptoms. Adolescents exhibited positive change in parent- report social problems and self-reported posttraumatic stress symptoms. These areas all bear importance for healthy functioning and minimizing future victimization, as prevention programs have noted lower revictimization rates when intervention targets avoidance, risk perception, emotional awareness, and beliefs about interpersonal violence (DePrince, Chu, Labus, Shirk, \& Potter, 2015; Hill, Vernig, Lee, Brown, \& Orsillo, 2011). Project SAFE serves a heterogeneous population, with children presenting as asymptomatic, sub-clinical, and with clinically significant psychological problems. In fact, median scores for the CBCL and YSR scales as well as the CITES PTSD scale and SEI were all within what may be considered the normal range, or at least fall below mean scores reported for clinical samples (Achenbach \& Rescorla, 2001; Coopersmith, 1981; Crouch et al., 1999). Thus, it is possible that a floor-or ceiling, in the case of the SEI-effect may have prevented significant improvement in symptoms over time.

Psychological distress at presentation to treatment was not associated with change in symptoms over the course of treatment, except in the case of child expectations of abuse impact. As children reported higher levels of distress, they exhibited less improvement in perceptions of abuse impact on functioning in a variety of life domains over the next 12 months. Although not explored in this study, it may be possible that expectations of abuse impact and distress are related through the mechanism of hopelessness. These negative expectations may also prevent children from using the healthy coping strategies that promote resilience (Wyman, Cowen, Work, \& Kerley, 1993). Therefore, the hypothesis that initial distress would predict response to treatment was scantly supported; however, expectations and perceptions about the future should be addressed in treatment for children reporting depression and anxiety after CSA. Although we cannot conclude that assessing distress as youth present to treatment will help us predict their response to intervention, gaining a sense of their depressive and anxiety symptoms through brief screening may help identify some specific and targetable symptoms.

The current study has several limitations. Notably, there was no measure of revictimization given the limited time frame within which assessment occurred (i.e., 3 months). The present study engaged in a necessary initial step toward understanding revictimization of youth: extending findings from the adult literature to child and adolescent samples. With evi- 
dence that these risk indicators are present in youth, further research should examine their value in predicting revictimization prior to reaching adulthood. The current project also relied on self- and parent-report of abuse. All families were referred to Project SAFE through the local CAC, with a majority of youth having completed a forensic interview prior to referral. CAC staff are thoroughly trained in working with these families and the researchers worked closely with CAC staff to make appropriate treatment referrals to Project SAFE. We did not include a control group to explore actual treatment effects as they differ from natural, time-related symptom reduction. It is recommended that youth receive treatment immediately following disclosure ( $\mathrm{Hsu}, 2003$ ), thus a wait-list control group may be considered unethical in that it prevents responsive intervention. The samples used in the current study were quite homogeneous in regard to gender ( $71 \%$ of children and $88 \%$ of adolescents were female) and ethnicity (80\% children and 77\% adolescents identified as European American). This lack of ethnic diversity resulted in collapsing minority ethnic groups into one group for analyses, which limits generalizability of the present findings and fails to recognize between-group differences for youth of varying ethnic identifications. Future research would benefit from inclusion of more diverse samples. In addition, this study focused solely on experiences of sexual abuse and did not measure comorbidity with other types of abuse experiences, preventing an examination of the effect of polyvictimization on functioning and risk. Finally, three adolescents were aged outside of standardization groups for the CITES-R and CDI (two participants aged 17 years and one aged 18 years), and Cronbach's alpha suggested poor or questionable internal consistency on a number of the measures used. All of these measures (i.e., CBCL, SEI, and CITES-R) have been used previously and demonstrated sound psychometric properties; however, the poor internal consistency with the present sample suggests that findings should be interpreted with caution.

When working with youth who have experienced CSA, it is important to consider many aspects of functioning as they relate to current mental health and future safety. Increasing practitioner knowledge of revictimization risk will enable intervention to serve as secondary prevention for CSA victims. The current findings suggest that many of the risk indicators outlined in adult revictimization literature are present in youth after first abuse occurrences and are associated with broad psychological distress, making initial screening and identification more feasible. Assessing for these issues after disclosure of abuse may help identify those in need of additional support and direct them to interventions that work to address 
abuse sequelae and prevent future abuse (Conners-Burrow et al., 2012). Preventive efforts may include the addition of brief screening measures in child advocacy organizations or child protection and safety intakes and communicating to caregivers the importance of seeking mental health support for youth after the experience of sexual abuse.

Future research should continue to prospectively explore revictimization throughout development in addition to showing how psychological intervention may act to reduce individual risk. The field has experienced a marked shift from simply exploring revictimization to preventing its occurrence through a better understanding of factors that direct the pathway from CSA to subsequent sexual victimization. Expanding focus to factors beyond the individual (i.e., family, school, and community factors) will also be important in developing adequate intervention as examining revictimization from an ecological framework may be helpful in understanding the etiology of subsequent abuse experiences. 


\section{Tables}

Table I. Summary Statistics of Risk Indicators and Significance of Related Samples Wilcoxon Signed Rank Tests Comparing Risk Indicators Pre- and Posttreatment.

\begin{tabular}{|c|c|c|c|c|c|c|c|c|c|c|}
\hline \multirow[b]{3}{*}{ Measure } & \multicolumn{5}{|c|}{ Children } & \multicolumn{5}{|c|}{ Adolescents } \\
\hline & \multicolumn{2}{|l|}{ Pre } & \multicolumn{2}{|l|}{ Post } & \multirow[b]{2}{*}{$p$} & \multicolumn{2}{|l|}{ Pre } & \multicolumn{2}{|l|}{ Post } & \multirow[b]{2}{*}{$p$} \\
\hline & $M(S D)$ & $M d n$ & $M(S D)$ & Mdn & & $M(S D)$ & Mdn & $M(S D)$ & Mdn & \\
\hline \multicolumn{11}{|l|}{ Risky behaviors } \\
\hline ACSBI-S & & & & & & $17.9(7.1)$ & 15.0 & $19.6(8.4)$ & 16.0 & .091 \\
\hline CBCL delinquency & $59.8(8.9)$ & 57.0 & $57.3(8.1)$ & 54.0 & .079 & $61.8(10.3)$ & 61.0 & $59.4(9.9)$ & 56.0 & .071 \\
\hline YSR delinquency & & & & & & $61.3(9.7)$ & 62.0 & $61.3(9.4)$ & 58.0 & .743 \\
\hline \multicolumn{11}{|l|}{ Interpersonal difficulties } \\
\hline WPS-C PPPI & $7.4(3.1)$ & 7.0 & $6.99(4.07)$ & 5.0 & $.036^{*}$ & $8.5(3.3)$ & 8.0 & $8.6(4.5)$ & 8.0 & .175 \\
\hline CBCL social problems & $59.9(11.0)$ & 57.0 & $58.2(10.1)$ & 24.0 & .948 & $58.0(8.1)$ & 58.0 & $55.8(7.6)$ & 55.0 & $.011^{*}$ \\
\hline YSR social problems & & & & & & $58.3(9.3)$ & 54.0 & $58.4(9.4)$ & 54.0 & .491 \\
\hline \multicolumn{11}{|l|}{ Maladaptive cognitions } \\
\hline CITES-R self-blame/guilt & $4.9(4.2)$ & 4.0 & $3.2(3.0)$ & 2.5 & $<.001^{* * *}$ & $5.5(4.2)$ & 5.0 & $4.3(3.8)$ & 3.0 & .055 \\
\hline CITES-R empowerment & $3.0(2.8)$ & 2.0 & $2.1(2.3)$ & 1.0 & $<.001^{* * k}$ & $3.7(2.5)$ & 3.0 & $3.4(2.8)$ & 4.5 & .180 \\
\hline PSAES-Y & $23.8(10.3)$ & 23.0 & $18.2(8.6)$ & 15.0 & $.007^{* * *}$ & $27.9(10.8)$ & 27.5 & $26.5(9.4)$ & 26 & .175 \\
\hline SEI & $64.8(18.0)$ & 67.0 & $71.5(18.0)$ & 74.0 & $.004 * *$ & $60.8(19.4)$ & 64.0 & $62.5(19.2)$ & 64.0 & .099 \\
\hline \multicolumn{11}{|c|}{ Posttraumatic stress symptoms } \\
\hline CITES-R PTSD & $28.3(9.7)$ & 29.0 & $22.9(9.8)$ & 22.0 & $<.001 * *$ & $26.3(9.2)$ & 27.0 & $21.6(9.3)$ & 22.0 & $<.001^{* * *}$ \\
\hline
\end{tabular}

Note. ACSBI-S = Adolescent Clinical Sexual Behavior Inventory-Self-Report; CBCL = Child Behavior Checklist; YSR = Youth Self-Report; WPS-C PPPI = Weekly Problems Scale-Child Report Version Problem Peer and Parental Interactions subscale; CITES-R = Children's Impact of Traumatic Events Scale-Revised; PSAES-Y = Post Sexual Abuse Expectations Scale-Youth; SEI = Self-Esteem Inventory; PTSD = posttraumatic stress disorder. $* p<.05$. **p $<.01$.

Table 2. Spearman's Rho Correlation Coefficients Between Demographic Information, Abuse Characteristics, Distress, and Risk Indicators in Children.

\begin{tabular}{|c|c|c|c|c|c|c|c|c|c|c|c|c|c|c|c|c|}
\hline & & 1 & 2 & 3 & 4 & 5 & 6 & 7 & 8 & 9 & 10 & 11 & 12 & 13 & 14 & 15 \\
\hline I. & Age (months) & - & & & & & & & & & & & & & & \\
\hline 2. & Gender & .008 & - & & & & & & & & & & & & & \\
\hline 3. & Ethnicity & -.003 & -.188 & - & & & & & & & & & & & & \\
\hline 4. & Penetration & .025 & -.187 & -.083 & - & & & & & & & & & & & \\
\hline 5. & Age at abuse onset & $.550^{\text {*ok }}$ & .101 & .163 & -.023 & - & & & & & & & & & & \\
\hline 6. & $\begin{array}{l}\text { Abuse duration } \\
\text { (months) }\end{array}$ & .048 & -.096 & .039 & .196 & $-.488 * *$ & - & & & & & & & & & \\
\hline 7. & $\begin{array}{l}\text { Perpetrator } \\
\text { relationship }\end{array}$ & .042 & .012 & .102 & .189 & -.215 & $.350^{*}$ \%* & - & & & & & & & & \\
\hline 8. & Distress & .149 & -.030 & -.156 & -.110 & .166 & .043 & -.137 & - & & & & & & & \\
\hline 9. & $\begin{array}{l}\mathrm{CBCL} \text { delinquent } \\
\text { behaviors }\end{array}$ & -.194 & -.178 & -.007 & -.073 & .040 & -.042 & $-.249 *$ & $.258 *$ & - & & & & & & \\
\hline 10. & WPS-C PPPI & $.273^{*}$ & -.038 & $.241^{*}$ & -.176 & .186 & -.056 & -.168 & $.269 *$ & $.275^{*}$ & - & & & & & \\
\hline 11. & CBCL social problems & .149 & -.083 & -.091 & .011 & .090 & .083 & $-.248 *$ & $.227^{*}$ & $.544^{\text {\%o }}$ & .197 & - & & & & \\
\hline 12. & CITES-R self-blame/guilt & -.038 & -.019 & -.089 & -.036 & -.027 & .017 & -.051 & $.449 \% *$ & .034 & .019 & $.213^{*}$ & - & & & \\
\hline 13. & CITES-R empowerment & -.110 & .048 & .048 & $-.306^{\text {*ok }}$ & -.004 & .033 & -.038 & $.299^{1 \% k}$ & .030 & -.006 & .043 & $.227^{*}$ & - & & \\
\hline & PSAES-Y & .028 & .095 & -.261 & .059 & .175 & -.015 & -.002 & $.471^{\text {*ok }}$ & .215 & .104 & .275 & $.354^{* \%}$ & $.350 *$ & - & \\
\hline 15. & SEI & -.117 & .068 & .115 & .074 & -.060 & -.097 & .048 & $-.764^{1 \% k}$ & $-.312^{\% * k}$ & $-.353^{\text {*ok }}$ & $-.256^{*}$ & $-.473^{\text {*k }}$ & $-.297^{\text {*ak }}$ & $-.447^{\text {*ak }}$ & - \\
\hline 16. & CITES-R PTSD & -.027 & .163 & -.116 & .031 & .188 & -.067 & -.010 & $.494^{\text {** }}$ & .045 & .046 & .153 & $.369 \%$ & .020 & $\left..43\right|^{\text {冰 }}$ & $-\left..39\right|^{* *}$ \\
\hline
\end{tabular}

Note. $\mathrm{CBCL}=$ Child Behavior Checklist; YSR = Youth Self-Report; WPS-C PPPI = Weekly Problems Scale Problem Peer and Parental Interactions subscale; CITES-R = Children's Impact of Traumatic Events Scale-Revised; PSAES-Y = Post Sexual Abuse Expectations Scale-Youth; SEI = Self-Esteem Inventory; PTSD = posttraumatic stress disorder.

${ }_{*} p<.05 .{ }^{* * k} p<.01$. 
Table 3. Spearman's Rho Correlation Coefficients Between Demographic Information, Abuse Characteristics, Distress, and Risk Indicators in Adolescents.

\begin{tabular}{|c|c|c|c|c|c|c|c|c|c|c|c|c|c|c|c|c|c|c|c|}
\hline & & I & 2 & 3 & 4 & 5 & 6 & 7 & 8 & 9 & 10 & 11 & 12 & 13 & 14 & 15 & 16 & 17 & 18 \\
\hline 1. & Age (months) & - & & & & & & & & & & & & & & & & & \\
\hline 2. & Gender & .066 & - & & & & & & & & & & & & & & & & \\
\hline 3. & Ethnicity & .243 & .005 & - & & & & & & & & & & & & & & & \\
\hline 4. & Penetration & -.049 & .090 & .078 & - & & & & & & & & & & & & & & \\
\hline 5. & $\begin{array}{l}\text { Age at abuse } \\
\text { onset }\end{array}$ & $.313^{*}$ & -.030 & -.073 & -.028 & - & & & & & & & & & & & & & \\
\hline 6. & $\begin{array}{l}\text { Abuse duration } \\
\text { (months) }\end{array}$ & .141 & .127 & $.407^{\text {tok }}$ & -.052 & $-.555^{\text {*ok }}$ & - & & & & & & & & & & & & \\
\hline 7. & $\begin{array}{l}\text { Perpetrator } \\
\text { relationship }\end{array}$ & -.103 & .229 & .071 & -.190 & $-.369^{*}$ & $.574^{* \%}$ & - & & & & & & & & & & & \\
\hline 8. & Distress & .110 & -.012 & $.305^{*}$ & .078 & .177 & .146 & .019 & - & & & & & & & & & & \\
\hline 9. & ACSBI-S & .114 & -.110 & .066 & .045 & -.003 & .136 & -.121 & $.382^{*}$ & - & & & & & & & & & \\
\hline 10. & $\begin{array}{l}\text { YSR delinquent } \\
\text { behaviors }\end{array}$ & .005 & -.019 & .022 & .169 & $.295^{*}$ & -.020 & -.125 & $.405^{\text {*ok }}$ & $.624^{*} *$ & $=-$ & & & & & & & & \\
\hline 11. & $\begin{array}{l}\mathrm{CBCL} \text { delinquent } \\
\text { behaviors }\end{array}$ & .060 & -.061 & -.083 & $.266^{*}$ & ". 191 & -.190 & -.239 & .154 & $.519 \%$ & $.675^{\text {’ok }}$ & - & & & & & & & \\
\hline 12. & WPS-C PPPI & .108 & -.022 & .184 & .130 & -.088 & .181 & -.102 & .167 & .261 & $.377^{* * *}$ & $.381^{* * *}$ & - & & & & & & \\
\hline 13. & $\begin{array}{l}\text { YSR social } \\
\text { problems }\end{array}$ & -.083 & -.153 & .110 & .009 & .102 & -.065 & -.011 & $.573^{\text {\%o }}$ & $.461 * *$ & $.417^{* * *}$ & $=.210$ & .072 & - & & & & & \\
\hline 14. & $\begin{array}{l}\mathrm{CBCL} \text { social } \\
\text { problems }\end{array}$ & -.090 & -.134 & -.062 & .119 & -.078 & -.127 & $-.265^{*}$ & .104 & .241 & .184 & $.323^{*}$ & .102 & .210 & - & & & & \\
\hline 15. & $\begin{array}{l}\text { CITES-R self- } \\
\text { blame/guilt }\end{array}$ & .128 & .170 & $.253 *$ & .031 & .161 & .126 & -.034 & $.425^{\mathrm{Hok}}$ & .200 & .065 & .010 & .025 & .211 & .137 & - & & & \\
\hline 16. & $\begin{array}{l}\text { CITES-R } \\
\text { empowerment }\end{array}$ & .050 & .011 & $.315^{*}$ & .095 & -.086 & .179 & -.088 & $.384^{* *}$ & .139 & .224 & $.256 *$ & .209 & .125 & .241 & .217 & - & & \\
\hline 17. & PSAES-Y & .036 & .257 & .007 & -.038 & -.184 & $.420 *$ & .122 & $.460^{\text {*2* }}$ & $.350 *$ & .195 & .147 & .189 & .298 & .183 & $.420^{* * k}$ & $* .059$ & - & \\
\hline 18. & SEI & -.037 & .053 & -.100 & .010 & -.125 & -.057 & -.065 & $-.813^{* *}-$ & $-.371 *$ & $-.379 * *$ & -.158 & -.084 & $-.543^{* *}$ & $-.285 *$ & $-.311 *$ & $-.40 I^{* *}$ & $*-.401 *$ & - \\
\hline 19. & CITES-R PTSD & -.105 & .114 & .111 & -.046 & -.051 & .074 & .020 & $.618^{\text {*k }}$ & .042 & .098 & .020 & .108 & $.413^{\text {*2k }}$ & .169 & $.424^{* k}$ & $* .163$ & 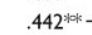 & $-.485^{* 11}$ \\
\hline
\end{tabular}

Note. YSR = Youth Self-Report; $C B C L=$ Child Behavior Checklist; WPS-C PPPI = Weekly Problems Scale Problem Peer and Parental Interactions subscale; CITES-R = Children's Impact of Traumatic Events Scale-Revised; PSAES-Y = Post Sexual Abuse Expectations Scale-Youth; SEI = Self-Esteem Inventory; PTSD = posttraumatic stress disorder.

$*_{p}<.05 .{ }^{* *} p<.01$. 
Table 4. Standardized Coefficients of Hierarchical Multiple Regression Models Using Distress to Predict Risk Indicators for Children.

\begin{tabular}{|c|c|c|c|c|c|c|c|c|c|}
\hline Criterion & $n$ & Step & Age & Ethnicity & Penetration & $\begin{array}{l}\text { Perpetrator } \\
\text { Relationship }\end{array}$ & Distress & $R^{2}$ & $\Delta R^{2}$ \\
\hline \multicolumn{10}{|l|}{ Pretreatment } \\
\hline \multirow[t]{2}{*}{$\mathrm{CBCL}$ delinquency } & 88 & 1 & -.142 & .014 & -.017 & $-.244^{*}$ & $0.282^{* k k}$ & .08 & $.07^{\text {* } \mathrm{k}}$ \\
\hline & & 2 & -0.204 & 0.055 & -0.008 & $-0.213^{*}$ & & $.16 *$ & \\
\hline \multirow[t]{2}{*}{ WPS-C PPPI } & 78 & 1 & $0.319 * *$ & $0.263^{*}$ & -0.105 & -0.173 & $0.236 *$ & $.21^{* * *}$ & $.05 *$ \\
\hline & & 2 & $0.268^{*}$ & $0.289^{\text {*k }}$ & -0.097 & -0.148 & & $.26^{* * *}$ & \\
\hline \multirow[t]{2}{*}{$\mathrm{CBCL}$ social problems } & 88 & 1 & -0.152 & -0.041 & 0.067 & $-0.274^{*}$ & 0.203 & .10 & .04 \\
\hline & & 2 & 0.108 & -0.011 & 0.074 & $-0.252 *$ & & $.13^{*}$ & \\
\hline \multirow[t]{2}{*}{ CITES-R self-blame/guilt } & 92 & 1 & -0.019 & -0.085 & 0.002 & -0.046 & $0.449 \%$ & .01 & $.18^{* \%}$ \\
\hline & & 2 & -0.117 & -0.019 & 0.016 & 0.002 & & $.20^{\text {*ok }}$ & \\
\hline \multirow[t]{2}{*}{ CITES-R empowerment } & 92 & 1 & -0.110 & 0.003 & 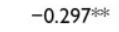 & 0.011 & $0.322^{* * *}$ & .10 & $.10^{* \%}$ \\
\hline & & 2 & -0.181 & 0.050 & $-0.287^{* * *}$ & 0.045 & & $.20 * *$ & \\
\hline \multirow[t]{2}{*}{ PSAES-Y } & 45 & 1 & 0.021 & -0.276 & 0.011 & 0.012 & $0.432^{* * *}$ & .08 & $.17^{* k *}$ \\
\hline & & 2 & -0.074 & -0.212 & 0.024 & 0.058 & & $.25 *$ & \\
\hline \multirow[t]{2}{*}{ SEI } & 92 & 1 & -0.131 & 0.140 & -0.005 & 0.048 & $-0.775^{\text {*ak }}$ & .04 & $.55^{* * \mathrm{k}}$ \\
\hline & & 2 & 0.039 & 0.025 & -0.030 & -0.034 & & $.59 \% *$ & \\
\hline \multirow[t]{2}{*}{ CITES-R PTSD } & 92 & 1 & .021 & -.121 & .058 & -.012 & $.538^{1 \%}$ & -.03 & $.27^{* 1 \% *}$ \\
\hline & & 2 & -.096 & -.042 & .075 & .045 & & $.24^{*}$ \% & \\
\hline \multicolumn{10}{|l|}{ Pre- to posttreatment change } \\
\hline \multirow[t]{2}{*}{$\mathrm{CBCL}$ delinquency } & 55 & 1 & -0.138 & -0.047 & 0.054 & 0.144 & 0.031 & .05 & .00 \\
\hline & & 2 & -0.145 & -0.043 & 0.055 & 0.147 & & .05 & \\
\hline \multirow[t]{2}{*}{ WPS-C PPPI } & 47 & 1 & -0.035 & $-0.369 \%$ & 0.006 & $0.3 I^{\text {k*k }}$ & -0.128 & $.25 * *$ & .02 \\
\hline & & 2 & -0.007 & $-0.387^{* * k}$ & 0.002 & $0.367 *$ & & $.27^{* *}$ & \\
\hline \multirow[t]{2}{*}{$\mathrm{CBCL}$ social problems } & 55 & 1 & $-0.293^{*}$ & 0.096 & -0.184 & 0.145 & 0.087 & .14 & .01 \\
\hline & & 2 & $-0.3 \mid 2^{*}$ & 0.109 & -0.181 & 0.155 & & .15 & \\
\hline \multirow[t]{2}{*}{ CITES-R self-blame/guilt } & 62 & 1 & -0.041 & -0.021 & 0.058 & -0.018 & -0.196 & .01 & .04 \\
\hline & & 2 & 0.001 & -0.050 & 0.051 & -0.039 & & .04 & \\
\hline \multirow[t]{2}{*}{ CITES-R empowerment } & 62 & 1 & -0.100 & -0.176 & 0.087 & 0.141 & $-0.294^{*}$ & .07 & $.08 *$ \\
\hline & & 2 & -0.036 & -0.220 & 0.078 & 0.109 & & .15 & \\
\hline \multirow[t]{2}{*}{ PSAES-Y } & 25 & 1 & 0.407 & 0.037 & -0.173 & 0.217 & $-0.459 *$ & .24 & $.19 *$ \\
\hline & & 2 & $0.507^{*}$ & -0.030 & -0.187 & 0.168 & & $.43^{*}$ & \\
\hline \multirow[t]{2}{*}{ SEI } & 61 & 1 & 0.023 & 0.065 & -0.114 & 0.074 & $0.292 *$ & .02 & $.08 *$ \\
\hline & & 2 & -0.041 & 0.108 & -0.105 & 0.105 & & .10 & \\
\hline \multirow[t]{2}{*}{ CITES-R PTSD } & 62 & 1 & -.029 & -.074 & -.050 & -.055 & -.151 & .01 & .02 \\
\hline & & 2 & .004 & -.096 & -.054 & -.072 & & .03 & \\
\hline
\end{tabular}

Note. $\mathrm{CBCL}=$ Child Behavior Checklist; WPS-C PPPI = Weekly Problems Scale-Child Report Version Problem Peer and Parental Interactions subscale; CITES-R = Children's Impact of Traumatic Events Scale-Revised; PSAES-Y = Post Sexual Abuse Expectations Scale-Youth; SEI = Self-Esteem Inventory; PTSD = posttraumatic stress disorder.

${ }^{*} p<.05 . *{ }^{*} p<.01$. 
Table 5. Standardized Coefficients of Hierarchical Multiple Regression Models Using Distress to Predict Risk Indicators for Adolescents.

\begin{tabular}{|c|c|c|c|c|c|c|c|c|c|c|}
\hline Criterion & $n$ & Step & $\begin{array}{c}\text { Age at Abuse } \\
\text { Onset }\end{array}$ & Ethnicity & Penetration & $\begin{array}{c}\text { Abuse } \\
\text { Duration }\end{array}$ & $\begin{array}{l}\text { Perpetrator } \\
\text { Relationship }\end{array}$ & Distress & $R^{2}$ & $\Delta R^{2}$ \\
\hline \multicolumn{11}{|l|}{ Pretreatment } \\
\hline \multirow[t]{2}{*}{ ACSBI-S } & 33 & 1 & 0.032 & -0.005 & 0.018 & 0.219 & -0.220 & 0.346 & .05 & .10 \\
\hline & & 2 & -0.088 & -0.094 & -0.011 & 0.145 & -0.208 & & .15 & \\
\hline \multirow[t]{2}{*}{ YSR delinquency } & 52 & 1 & $0.382^{*}$ & 0.032 & 0.142 & 0.134 & -0.035 & $0.402^{* * *}$ & .12 & $.14 \%$ \\
\hline & & 2 & 0.244 & -0.072 & 0.109 & 0.048 & -0.021 & & $.25^{*}$ & \\
\hline \multirow[t]{2}{*}{ CBCL delinquency } & 54 & 1 & 0.195 & -0.092 & $0.296 *$ & 0.039 & -0.147 & 0.137 & .17 & .016 \\
\hline & & 2 & 0.148 & -0.128 & $0.285^{*}$ & 0.010 & -0.142 & & .18 & \\
\hline \multirow[t]{2}{*}{ WPS-C PPPI } & 53 & 1 & 0.019 & 0.127 & 0.075 & 0.297 & -0.233 & 0.112 & .12 & .01 \\
\hline & & 2 & -0.020 & 0.098 & 0.066 & 0.273 & -0.230 & & .13 & \\
\hline \multirow[t]{2}{*}{ YSR social problems } & 52 & 1 & 0.125 & 0.155 & 0.038 & -0.111 & 0.055 & $0.632 * *$ & .05 & $.34 \%$ \\
\hline & & 2 & -0.092 & -0.008 & -0.015 & -0.247 & 0.077 & & $.39 * *$ & \\
\hline \multirow{2}{*}{$\begin{array}{l}\text { CBCL social } \\
\text { problems }\end{array}$} & 54 & 1 & -0.231 & -0.027 & 0.048 & -0.131 & -0.239 & 0.227 & .09 & .04 \\
\hline & & 2 & -0.309 & -0.086 & 0.029 & -0.180 & -0.231 & & .14 & \\
\hline \multirow{2}{*}{$\begin{array}{l}\text { CITES-R self-blame/ } \\
\text { guilt }\end{array}$} & 56 & 1 & 0.216 & 0.244 & -0.041 & 0.164 & -0.054 & $0.347^{*}$ & .10 & $.10 *$ \\
\hline & & 2 & 0.097 & 0.154 & -0.070 & 0.089 & -0.042 & & .20 & \\
\hline \multirow{2}{*}{$\begin{array}{l}\text { CITES-R } \\
\text { empowerment }\end{array}$} & 56 & 1 & 0.028 & $0.282^{*}$ & 0.067 & 0.205 & -0.229 & $0.359 *$ & .16 & $.11 *$ \\
\hline & & 2 & -0.096 & 0.189 & 0.037 & 0.128 & -0.217 & & $.27^{*}$ & \\
\hline \multirow[t]{2}{*}{ PSAES-Y } & 32 & 1 & 0.039 & -0.175 & -0.102 & 0.522 & -0.134 & $0.530 * *$ & .18 & $.24 * *$ \\
\hline & & 2 & -0.143 & -0.312 & -0.146 & 0.407 & -0.116 & & $.42^{*}$ & \\
\hline \multirow[t]{2}{*}{ SEI } & 55 & 1 & 0.314 & 0.204 & 0.012 & 0.208 & -0.010 & $0.552^{* *}$ & .03 & $.68^{* \alpha k}$ \\
\hline & & 2 & 0.124 & 0.061 & -0.034 & 0.089 & 0.010 & & $.71 * *$ & \\
\hline \multirow[t]{2}{*}{ CITES-R PTSD } & 54 & 1 & -.031 & .151 & -.058 & -.108 & .054 & $.732 * *$ & .03 & $.45 \%$ \\
\hline & & 2 & -.282 & -.039 & -.119 & -.266 & .080 & & $.48^{* * *}$ & \\
\hline \multicolumn{11}{|c|}{ Pre- to posttreatment change } \\
\hline \multirow[t]{2}{*}{ ACSBI-S } & 20 & 1 & 0.311 & 0.118 & -0.251 & 0.410 & 0.228 & -0.060 & .32 & .00 \\
\hline & & 2 & 0.331 & 0.133 & -0.246 & 0.423 & 0.226 & & .32 & \\
\hline \multirow[t]{2}{*}{ YSR delinquency } & 37 & 1 & -0.219 & -0.098 & -0.208 & -0.281 & -0.040 & 0.070 & .12 & .00 \\
\hline & & 2 & -0.243 & -0.116 & -0.214 & -0.296 & -0.037 & & .12 & \\
\hline \multirow[t]{2}{*}{$\mathrm{CBCL}$ delinquency } & 38 & 1 & -0.112 & 0.164 & -0.250 & -0.193 & 0.050 & 0.273 & .10 & .06 \\
\hline & & 2 & -0.206 & 0.094 & -0.273 & -0.252 & 0.059 & & .16 & \\
\hline \multirow[t]{2}{*}{ WPS-C PPPI } & 32 & 1 & 0.167 & -0.260 & 0.093 & 0.228 & -0.250 & 0.145 & .13 & .01 \\
\hline & & 2 & 0.118 & -0.297 & 0.081 & 0.197 & -0.245 & & .14 & \\
\hline \multirow[t]{2}{*}{ YSR social problems } & 37 & 1 & -0.129 & $-0.467^{\text {**k }}$ & -0.037 & -0.172 & 0.122 & 0.017 & .27 & .00 \\
\hline & & 2 & -0.135 & $-0.472 * *$ & -0.038 & -0.176 & 0.113 & & .27 & \\
\hline \multirow{2}{*}{$\begin{array}{l}\text { CBCL social } \\
\text { problems }\end{array}$} & 38 & 1 & 0.230 & -0.032 & 0.011 & 0.073 & -0.001 & 0.179 & .04 & .02 \\
\hline & & 2 & 0.168 & -0.078 & -0.004 & 0.034 & 0.006 & & .06 & \\
\hline \multirow{2}{*}{$\begin{array}{l}\text { CITES-R self-blame/ } \\
\text { guilt }\end{array}$} & 41 & I & -0.117 & -0.128 & 0.113 & 0.020 & 0.099 & 0.103 & .06 & .01 \\
\hline & & 2 & -0.153 & -0.154 & 0.105 & -0.002 & 0.102 & & & .07 \\
\hline CITES-R & 41 & I & 0.131 & -0.177 & -0.074 & 0.061 & 0.046 & -0.085 & .05 & .01 \\
\hline empowerment & & 2 & 0.161 & -0.155 & -0.067 & 0.079 & 0.043 & & .06 & \\
\hline PSAES-Y & 18 & 1 & -0.038 & -0.319 & 0.233 & -0.018 & 0.176 & -0.117 & .16 & .01 \\
\hline & & 2 & 0.003 & -0.288 & 0.243 & 0.008 & 0.171 & & .17 & \\
\hline SEI & 41 & I & 0.114 & 0.213 & -0.055 & -0.092 & 0.207 & 0.172 & .09 & .02 \\
\hline & & 2 & 0.055 & 0.168 & -0.069 & -0.129 & 0.213 & & .11 & \\
\hline CITES-R PTSD & 41 & 1 & .049 & .062 & .169 & .032 & .108 & -.069 & -.10 & .15 \\
\hline & & 2 & .073 & .080 & .175 & .047 & .106 & & -.12 & \\
\hline
\end{tabular}

Note. ACSBI-S = Adolescent Clinical Sexual Behavior Inventory-Self-Report; YSR = Youth Self-Report; CBCL = Child Behavior Checklist; WPS-C PPPI = Weekly Problems Scale-Child Report Version Problem Peer and Parental Interactions subscale; CITES-R = Children's Impact of Traumatic Events Scale-Revised; PSAES-Y = Post Sexual Abuse Expectations Scale-Youth; SEI = Self-Esteem Inventory; PTSD = posttraumatic stress disorder. ${ }^{*} p<.05 .{ }^{* *} p<.01$ 
Declaration of Conflicting Interests - The authors received no financial support and have declared no potential conflicts of interest with respect to the research, authorship, or publication of this article.

\section{References}

Achenbach, T. M., \& Rescorla, L. A. (2001). Manual for the ASEBA school-age forms \& profiles. Burlington: University of Vermont Press.

Arata, C. M. (2002). Child sexual abuse and sexual revictimization. Clinical Psychology: Science and Practice, 9, 135-164. doi:10.1093/clipsy.9.2.135

Avinger, K. A., \& Jones, R. A. (2007). Group treatment of sexually abused adolescent girls: A review of outcome studies. The American Journal of Family Therapy, 35, 315-326. doi:10.1080/01926180600969702

Blom, G. (1958). Statistical estimates and transformed beta-variables. New York, NY: Wiley.

Bramsen, R. H., Lasgaard, M., Koss, M. P., Shevlin, M., Elklit, A., \& Banner, J. (2013). Testing a multiple mediator model of the effect of childhood sexual abuse on adolescent sexual victimization. American Journal of Orthopsychiatry, 83, 47-54. doi:10.1111/ajop.12011

Celano, M., Hazzard, A., Webb, C., \& McCall, C. (1996). Treatment of traumagenic beliefs among sexually abused girls and their mothers: An evaluation study. Journal of Abnormal Child Psychology, 24, 1-17. doi:10.1007/BF01448370

Centers for Disease Control and Prevention. (2010). Adverse childhood experiences (ACE) study: Data and statistics. http://www.cdc.gov/ace/prevalence.htm

Chaffin, M., \& Shultz, S. K. (2001). Psychometric evaluation of the Children's Impact of Traumatic Events Scale-Revised. Child Abuse \& Neglect, 25, 401-411. doi:10.1016/So145-2134(00)00257-X

Chu, J. A. (1992). The revictimization of adult women with histories of childhood abuse. Journal of Psychotherapy Practice and Research, 1, 259-269.

Classen, C. C., Palesh, O. G., \& Aggarwal, R. (2005). Sexual revictimization: A review of the empirical literature. Trauma, Violence, \& Abuse, 6, 103-129. doi:10.1177/088626001016006001

Cloitre, M. (1998). Sexual revictimization: Risk factors and prevention. In V. M. Follette, J. I. Ruzek, \& F. R. Abueg (Eds.), Cognitive-behavioral therapies for trauma (pp. 278-304). New York, NY: Guilford Press.

Cloitre, M., Scarvalone, P., \& Difede, J. (1997). Posttraumatic stress disorder, selfand interpersonal dysfunction among sexually retraumatized women. Journal of Traumatic Stress, 10, 437-452. doi:10.1002/jts.2490100309

Collins, M. E. (1998). Factors influencing sexual victimization and revictimization in a sample of adolescent mothers. Journal of Interpersonal Violence, 13, 3-24. doi:10.1177/088626098013001001

Conners-Burrow, N. A., Tempel, A. B., Sigel, B. A., Church, J. K., Kramer, T. L., \& Worley, K. B. (2012). The development of a systematic approach to mental 
health screening in child advocacy centers. Children and Youth Services Review, 34, 1675-1682. doi:0.1016/j.childyouth.2012.04.020

Coopersmith, S. (1981). Coopersmith Self-Esteem Inventories. Mountain View, CA: Consulting Psychologists Press.

Corder, B. F., Haizlip, T., \& DeBoer, P. (1990). A pilot study for a structured, timelimited therapy group for sexually abused pre-adolescent children. Child Abuse \& Neglect, 14, 243-251. doi:10.1016/0145-2134(90)90035-R

Crouch, J. L., Smith, D. W., Ezzell, C. E., \& Saunders, C. E. (1999). Measuring reactions to sexual trauma among children: Comparing the Children's Impact of Traumatic Events Scale and the Trauma Symptom Checklist for Children. Child Maltreatment, 4, 255-263. doi:10.1177/1077559599004003006

Cuevas, C. A., Finkelhor, D., Clifford, C., Ormrod, R. K., \& Turner, H. A. (2010). Psychological distress as a risk factor for re-victimization in children. Child Abuse \& Neglect, 34, 235-243. doi:10.1016/j.chiabu.2009.07.004

Deblinger, E., Mannarino, A. P., Cohen, J. A., \& Steer, R. A. (2006). A follow-up study of a multisite, randomized, controlled trial for children with sexual abuserelated PTSD symptoms. Journal of the American Academy of Child \& Adolescent Psychiatry, 45, 1474-1484. doi:10.1097/01.chi.00o0240839.56114.bb

DePrince, A. P., Chu, A. T., Labus, J., Shirk, S. R., \& Potter, C. (2015). Testing two approaches to revictimization prevention among adolescent girls in the child welfare system. Journal of Adolescent Health, 56, 533-539. doi:10.1016/j.jadohealth.2014.06.022

Fargo, J. D. (2009). Pathways to adult sexual revictimization: Direct and indirect behavioral risk factors across the lifespan. Journal of Interpersonal Violence, 24, 1771-1791. doi:10.1177/o886260508325489

Fergusson, D. M., Horwood, L. J., \& Lynskey, M. T. (1997). Childhood sexual abuse, adolescent sexual behaviors and sexual revictimization. Child Abuse \& Neglect, 21(8), 789-803. doi:10.1016/So145-2134(97)ooo39-2

Filipas, H. H., \& Ullman, S. E. (2006). Child sexual abuse, coping responses, selfblame, posttraumatic stress disorder, and adult sexual revictimization. Journal of Interpersonal Violence, 21, 652-672. doi:10.1177/0886260506286879

Finkelhor, D., \& Browne, A. (1985). The traumatic impact of child sexual abuse: A conceptualization. American Journal of Orthopsychiatry, 55, 530-541.

Finkelhor, D., Ormrod, R. K., \& Turner, H. A. (2007). Re-victimization patterns in a national longitudinal sample of children and youth. Child Abuse \& Neglect, 31, 479-502. doi:10.1016/j.chiabu.2006.03.012

Fortier, M. A., DiLillo, D., Messman-Moore, T. L., Peugh, J., DeNardi, K. A., \& Gaffey, K. J. (2009). Severity of child sexual abuse and revictimization: The mediating role of coping and trauma symptoms. Psychology of Women Quarterly, 33, 308320. doi:10.1111/j.1471-6402.2009.01503.X

Friedrich, W. N., Lysne, M., Sim, L., \& Shamos, S. (2004). Assessing sexual behavior in high-risk adolescents with the Adolescent Clinical Sexual Behavior Inventory. Child Maltreatment, 9, 239-250. doi:10.1177/1077559504266907

Hill, J. M., Vernig, P. M., Lee, J. K., Brown, C., \& Orsillo, S. M. (2011). The develop- 
ment of a brief acceptance and mindfulness-based program aimed at reducing sexual revictimization among college women with a history of childhood sexual abuse. Journal of Clinical Psychology, 67, 969-981. doi:10.1002/jclp.20813

Holm, S. (1979). A simple sequentially rejective multiple test procedure. Scandinavian Journal of Statistics, 6, 65-70.

Hsu, E. (2003). Parallel group treatment for sexually abused children and their nonoffending parents: An examination of treatment integrity and child and family outcome and satisfaction (Doctoral dissertation, The University of NebraskaLincoln). http://digitalcommons.unl.edu/dissertations/AAI3092555/

Hubel, G. S., Campbell, C., West, T., Friedenberg, S., Schreier, A., Flood, M. F., \& Hansen, D. J. (2014). Child advocacy center based group treatment for child sexual abuse. Journal of Child Sexual Abuse, 23, 304-325. doi:10.1080/10538712. 2014.888121

IBM Corp. (2013). IBM SPSS Statistics for Windows, Version 22.0. Armonk, NY: Author.

Kovacs, M. (1992). Children's Depression Inventory. Toronto, Ontario, Canada: Multi-Health Systems.

Krahe, B., Scheinberger-Olwig, R., Waizenhöfer, E., \& Kolpin, S. (1999). Childhood sexual abuse and revictimization in adolescence. Child Abuse \& Neglect, 23, 383394. doi:10.1016/So145-2134(99)0ooo2-2

Lam, D., Schuck, N., Smith, N., Farmer, A., \& Checkley, S. (2003). Response style, interpersonal difficulties and social functioning in major depressive disorder. Journal of Affective Disorders, 75, 279-283. doi:10.1016/S0165-0327(02)00058-7

Marx, B. P., Calhoun, K. S., Wilson, A. E., \& Meyerson, L. A. (2001). Sexual revictimization prevention: An outcome evaluation. Journal of Consulting and Clinical Psychology, 69, 25-32. doi:10.1037/0022-006X.69.1.25

Meidlinger, K., West, T., Pittenger, S., Schreier, A., Pogue, J., Flood, M. F., \& Hansen, D. (2014, November). Assessing children's expectations post sexual abuse: Initial psychometric evaluation of a self-report measure. Poster presented at the 48th Annual Convention of the Association for Behavioral and Cognitive Therapies, Philadelphia, PA.

Orcutt, H. K., Cooper, M. L., \& Garcia, M. (2005). Use of sexual intercourse to reduce negative affect as a prospective mediator of sexual revictimization. Journal of Traumatic Stress, 18, 729-739.

Peterson, C., \& Seligman, M. E. P. (1983). Learned helplessness and victimization. Journal of Social Issues, 39, 103-116.

Putnam, F. W. (2003). Ten-year research update review: Child sexual abuse. Journal of the American Academy of Child \& Adolescent Psychiatry, 42, 269-278. doi:10.1097/00004583-200303000-00006

Reynolds, C. R., \& Richmond, B. O. (1978). What I think and feel: A revised measure of children's manifest anxiety. Journal of Abnormal Child Psychology, 6, 271-280.

Reynolds, C. R., \& Richmond, B. O. (1985). Revised Children's Manifest Anxiety Scale (RCMAS): Manual. Los Angeles, CA: Western Psychological Services. 
Risser, H. J., Hetzel-Riggin, M. D., Thomsen, C. J., \& McCanne, T. R. (2006). PTSD as a mediator of sexual revictimization: The role of reexperiencing, avoidance, and arousal symptoms. Journal of Traumatic Stress, 19, 687-698. doi:10.1002/ jts. 20156

Sawyer, G. K., \& Hansen, D. J. (2014). Heterogeneous symptom patterns of sexually abused children in treatment: Understanding the complexity of the problem. Journal of Child Sexual Abuse, 23, 900-917. doi:10.1080/10538712.2014.964439

Sawyer, G. K., Tsao, E. H., Hansen, D. J., \& Flood, M. F. (2006). Weekly problems scales: Instruments for sexually abused youth and their nonoffending parents in treatment. Child Maltreatment, 11, 34-48. doi:10.1177/1077559505283550

Sturkie, K. (1994). Group treatment of sexually abused children: Clinical wisdom and empirical findings. Child \& Adolescent Psychiatric Clinics of North America, 3, 813-829.

Swanston, H. Y., Parkinson, P. N., Oates, R. K., O’Toole, B. I., Plunkett, A. M., \& Shrimpton, S. (2002). Further abuse of sexually abused children. Child Abuse \& Neglect, 26, 115-127.

Tavkar, P., \& Hansen, D. J. (2011). Interventions for families victimized by child sexual abuse: Clinical issues and approaches for child advocacy center- based services. Aggression and Violent Behavior, 16, 188-199. doi:10.1016/j. avb.2011.02.005

Verhulst, F. C., \& van der Ende, J. (1992). Six-year developmental course of internalizing and externalizing problem behaviors. Journal of the American Academy of Child \& Adolescent Psychiatry, 31, 924-931.

Wenninger, K., \& Ehlers, A. (1998). Dysfunctional cognitions and adult psychological functioning in child sexual abuse survivors. Journal of Traumatic Stress, 11, 281-300. doi:10.1023/A:1024451103931

Wolfe, V. V., Gentile, C., Michienzi, T., Sas, L., \& Wolfe, D. A. (1991). The Children's Impact of Traumatic Events Scale: A measure of post-sexual abuse PTSD symptoms. Behavioral Assessment, 13, 359-383.

Wyman, P. A., Cowen, E. L., Work, W. C., \& Kerley, J. H. (1993). The role of children's future expectations in self-system functioning and adjustment to life stress: A prospective study of urban at-risk children. Development and Psychopathology, 5, 649-661. doi:10.1017/So954579400006210 


\section{Author Biographies}

Samantha L. Pittenger, MA, is a doctoral candidate in the Clinical Psychology Training Program at the University of Nebraska-Lincoln. Her research interests include prevention and treatment of child abuse and neglect with particular focus on individual, familial, community, and system-level impact on risk for repeat victimization.

Alayna Schreier, MA, is a predoctoral intern at the University of Arkansas for Medical Sciences and a doctoral candidate in Clinical Psychology at the University of Nebraska-Lincoln. Her research interests include prevention and intervention for at- risk and maltreating families, early childhood intervention programs, and policy related to child welfare.

Katie Meidlinger, MA, is a graduate student in the Clinical Psychology Training Program at the University of Nebraska-Lincoln. Her interests include the purveyance of trauma informed care for youth victims of abuse and measure development for purposes of informing clinical care for victims of sexual abuse.

Jessica K. Pogue, MA, is a clinical psychology graduate student at the University of Nebraska-Lincoln. Her primary research interests include child maltreatment, early childhood development, and the promotion of access to mental health services.

Kate Theimer, MA, is a clinical psychology graduate student at the University of Nebraska-Lincoln. Her clinical and research interests include the assessment and intervention of child maltreatment, the correlates and outcomes of child maltreatment, and the factors of maltreatment that influence attributions of responsibility.

Mary Fran Flood, PhD, is a lecturer of psychology at the University of NebraskaLincoln. Her primary research focus is on the prevention of child maltreatment and improving mental health services in Head Start settings. Additional interests include the heterogeneous impact of sexual abuse, factors that influence outcomes in sexual abuse, and developing and evaluating measures and treatments for sexual abuse victims and their families.

David J. Hansen, $\mathrm{PhD}$, is professor of psychology, director of clinical training, and director of the Center for Brain, Biology and Behavior at the University of Nebraska- Lincoln. His primary research area is child maltreatment (sexual abuse, physical abuse, and neglect), including assessment and intervention with victims and families, and the consequences and prevention of maltreatment. 